\title{
The Microphase-separated Structure of Polyurethane Bulk and Thin Films
}

\author{
By Ken KOJIO, ${ }^{1}$ So KUGUMIYA, ${ }^{2}$ Yusuke UCHIBA, ${ }^{2}$ \\ Yuichi NISHINO, ${ }^{2}$ and Mutsuhisa FURUKAWA ${ }^{2, *}$
}

The microphase-separated structure of polyurethane bulk and thin films were investigated using atomic force microscopy (AFM). The polyurethane (PUs) were synthesized with poly(oxytetramethylene) glycol (PTMG), 4,4'-diphenylmethane diisocyanate (MDI) and 1,4-butanediol (BD) by a prepolymer method. The hard segment contents were 34 and $45 \mathrm{wt} \%$. Polarized optical microscopy (POM) revealed that the $34 \mathrm{wt} \%$ PUE is homogeneous at a macroscopic level, while the $45 \mathrm{wt} \%$ one is macrophase-separated into two phases. One phase forms spherulites of $c a .2-5 \mu \mathrm{m}$ in diameter. AFM observation for the $34 \mathrm{wt} \%$ PUE showed the microphase-separated structure, consisting of hard segment domains and a soft segment matrix. In contrast, for the $45 \mathrm{wt} \%$ PUE, a lot of the hard segment domains were observed in the spherulite region, indicating that spherulites include much amount of hard segment component, in contrast, outside of spherulite exhibited similar structure to that of $34 \mathrm{wt} \%$ one. For the PU bulk, the different microphase-separated structure in the inside and outside of spherulite was successfully observed for the first time. Also, the microphase-separated structure of PU films was investigated as a function of the film thickness. The PU films exhibited similar microphase-separated structure. For the thicker film $(\sim 200 \mathrm{~nm})$, the interdomain spacing almost corresponded to bulk one. On the other hand, that for the film thickness below $7 \mathrm{~nm}$ dramatically decreased. This seems to be simply related to a decreasing space. We obtained the experimental data, which the phase-separated domain size of multiblock copolymer decreased with decreasing film thickness. KEY WORDS: Polyurethane / Microphase-separated Structure / Atomic Force Microscopy / Thin Film /

A microphase-separated structure formed in polymers plays a quite important role for their properties, such as electric, adsorption, mechanical properties. To form the microphaseseparated structure in polymers, they need to possess block structures, which are chemically connected each other. It is well-known that the polyurethane elastomers (PUEs), which possess the multiblock structure, show the microphase-separated structure, ${ }^{1-6}$ resulting in giving some unique properties, such as mechanical and adhesive properties ${ }^{6-16}$ and biocompatibility. ${ }^{17}$

To functionalize the PUs with the microphase-separated structure, one needs to control the structures precisely. There has been reported some factors to control the microphaseseparated structure. A polymerization method, ${ }^{13}$ thermal treatment $^{3,14}$ and chemical structures of raw materials including molecular weight ${ }^{6-12,15,16}$ can be given as examples. First, by changing the polymerization method, one can control the primary structure of the PUs. The representative polymerization methods for the PUs are a prepolymer method and a oneshot one. When the PUEs are synthesized by a prepolymer method, the ordering block structure is slightly higher in comparison with that by a one-shot method. The ordering of the primary structure strongly affects final structure as well as an aggregation property among each component. Second, thermal treatment usually progresses the degree of microphase separation. ${ }^{3,14}$ For instance, when the PUs are annealed at a certain temperature, the hard segment domains with melting point above the annealing temperature would be progressed. Finally, by annealing a proper temperature, the microphaseseparated structure is closed to the equilibrium state. Third, a chemical structure is quite important factor because it directly influences interaction between two components, that is, enthalpic term of the Gibbs free energy of mixing. Furthermore, molecular weight of the soft segment part is dominant factor since higher molecular weight easily forms a rich phase on account of entropic contribution. Because the size of the microphase-separated structure is nanometer scale, the PU can be classified "nanostructured material."

For the past decade, many researchers have focused on the structure and properties of the thin polymer films as an important key technology in nanoscale science. This is the case even for the PU. The PUs usually possess the microphaseseparated structure with interdomain spacing of $10-20 \mathrm{~nm}$. What is going on if the film thickness is smaller than the spacing? Generally, block copolymers loose the microphaseseparated structure with the thickness which is smaller than the periodic structure, or forms an island structure, in which the periodic structure exists. ${ }^{18}$ On the contrary, since the PU has strong polar groups in the main chain, a multiblock structure and distribution of each block length, it is expected that a new phenomenon will be occurred in the thin film.

In this study, the microphase-separated structure of the PU bulk and thin films were investigated by atomic force microscopy (AFM). For the PU bulk, we paid an attention on the

\footnotetext{
${ }^{1}$ Department of Materials Science and Engineering, Faculty of Engineering, Nagasaki University, 1-14 Bunkyo-machi, Nagasaki 852-8521, Japan

${ }^{2}$ Department of Materials Science, Graduate School of Science and Technology, Nagasaki University, 1-14 Bunkyo-machi, Nagasaki 852-8521, Japan

${ }^{*}$ To whom correspondence should be addressed (Tel: +81-95-819-2650, Fax: +81-95-819-2651, E-mail: Furukawa@ nagasaki-u.ac.jp).
} 
spherulite structure, which is a typical macrophase-separated structure. We also focused on the film thickness dependence of the microphase-separated structure of the PU thin and ultrathin films.

\section{EXPERIMENT}

\section{Materials}

Poly(oxytetramethylene) glycol (PTMG: $M_{\mathrm{n}}=2000$, Asahikasei Chemicals Co., Ltd., Japan), 4,4'-diphenylmethane diisocyanate (MDI, Nippon Polyurethane Industry Co., Ltd., Japan) and 1,4-butanediol (BD, Wako Chemicals Co., Ltd., Japan) were used as a polymer glycol, diisocyanate and chain extender, respectively. BD was refluxed with calcium hydride to remove water and subsequently distilled for purification. MDI was used without further purification.

\section{Synthesis of PUs}

The PUs were synthesized by a bulk prepolymer method. The PTMG were dried with dried nitrogen under a reduced pressure. Prepolymers were prepared from PTMG and MDI with a ratio of $\mathrm{K}=[\mathrm{NCO}] /[\mathrm{OH}]=3.3$ and 5.3 at $80^{\circ} \mathrm{C}$ for $3 \mathrm{~h}$ under a nitrogen atmosphere. The extent of reaction was pursued by an amine equivalent method. After finishing the reaction, the prepolymer was placed in vacuum to remove air involved in it. The prepolymer and curing agent were mixed well with a ratio of $[\mathrm{NCO}]_{\text {pre }} /[\mathrm{OH}]=1.05$ for $90 \mathrm{~s}$ and the viscous product was poured into a mold constructed by a spacer of $2 \mathrm{~mm}$ thickness and two aluminum plates heated at $80^{\circ} \mathrm{C}$, where $[\mathrm{NCO}]_{\text {pre }}$ is the concentration of $\mathrm{NCO}$ groups in a prepolymer. The PUs were demolded after $2 \mathrm{~h}$ curing, and then, they were post-cured at $80^{\circ} \mathrm{C}$ for $24 \mathrm{~h}$ in air. In order to compare the effect of the hard segment contents on the microphase-separated structure, we obtained two PUs with the hard segment contents of 34 and $45 \mathrm{wt} \%$. Nomenclature denotes hard segment content and the initial of bulk and film. For AFM observation, the PU sheets were sliced, and then, a cross section was fixed on a silicon wafer substrate.

\section{Thin Film Preparation}

The thin PU films were prepared onto a silicon wafer from the tetrahydrofuran PU solution by a spin coating method. The spinning rate was $3000 \mathrm{rpm}$. Then, the samples were dried under vacuum to remove residual solvent. Film thickness was controlled by changing solution concentration from 0.15 to 3 wt $\%$.

\section{Fourier-tranform Infrared (FT-IR) Spectroscopy}

FT-IR spectra were collected using a Biorad FTS-3000 equipped with a mercury-cadmium-telluride detector to investigate the degree of hydrogen bonding of the hard segment chains and the molecular orientation in the PU films. For the bulk sample, attenuated total reflection (ATR) method was taken using an ATR cell (MIRacle, PIKE Technologies, Inc. USA). Spectra were collected with 32 scans and at a resolution of $4 \mathrm{~cm}^{-1}$. For the thin films, spectra were obtained by a transmission mode. As a substrate, a double side polished silicon wafer was employed. p-Polarized infrared beam was used and incident angles were 10 and $74^{\circ}$. Spectra were collected with 512 scans and at a resolution of $4 \mathrm{~cm}^{-1}$.

\section{Differential Scanning Calorimetry (DSC)}

Differential scanning calorimetric (DSC) measurement was performed to understand the thermal behavior of the PUEs. DSC thermograms were obtained with a DSC (DSC 8230, Rigaku Denki, Co., Ltd. Japan) in the temperature rage from -130 to $250{ }^{\circ} \mathrm{C}$ with a heating rate of $10^{\circ} \mathrm{C} \mathrm{min}^{-1}$ under nitrogen atmosphere. As-prepared samples were simply cooled down around $-140^{\circ} \mathrm{C}$, and then, measurement was started.

\section{Polarized Optical Microscopy (POM)}

Direct observation of aggregation structure in the FGPUEs was carried out using a polarized optical microscope (POM) at $20^{\circ} \mathrm{C}$. POM (OPTIPHOTP2-POL, Nikon, Co., Ltd.) was employed for this observation.

\section{Small Angle X-ray Scattering (SAXS)}

In order to investigate the microphase-separated state of PU bulk samples, SAXS measurement performed. A rotating anode generator (Rigaku, Ltd. Co., Japan) was used as an X-ray source. The wavelength of the incident X-ray was $0.154 \mathrm{~nm}$ and the camera length was $1717 \mathrm{~mm}$.

\section{X-Ray Photoelectron Spectroscopy (XPS)}

XPS measurement was carried out to analyze the surface chemical composition of the PU films. PHI 5800 (Phyisical Electronics, Inc., USA) with monochromated X-ray source was employed. Emission angle employed were 75 and $30^{\circ}$, corresponding analytical depths of 10.1 and $5.3 \mathrm{~nm}$, respectively.

\section{Observation of the Microphase-separated Structure}

The microphase-separated structure of the PU films was observed using a Seiko Instrument AFM. AFM (SPA 400 equipped with SPI 3800N controller: Seiko Instruments Industry, Co., Ltd., Japan) was operated under intermittent mode, using a $20 \mu \mathrm{m} \times 20 \mu \mathrm{m}$ scanner and Si tip on cantilever with a bending spring constant of $14 \mathrm{~N} \mathrm{~m}^{-1}$ and resonance frequency of $138 \mathrm{kHz}$. Since the PU includes the rubbery soft segments at room temperature, we took an intermittent mode for the observation. Both topography and phase images were collected. To avoid the destruction of the sample surface, the images were acquired under ambient condition using light to moderate tapping, $r=0.90-0.80$, where $r=$ (set point amplitude/free amplitude of oscillation).

\section{RESULTS AND DISCUSSION}

\section{Bulk Samples}

To confirm the degree of microphase separation of the PUs prepared in this study, we carried out FT-IR and DSC measurements. Figure 1 shows the ATR-FT-IR spectra of the 


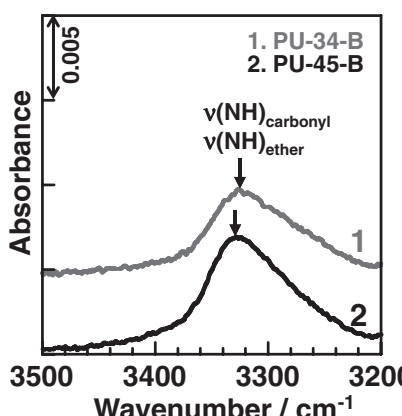

(a)

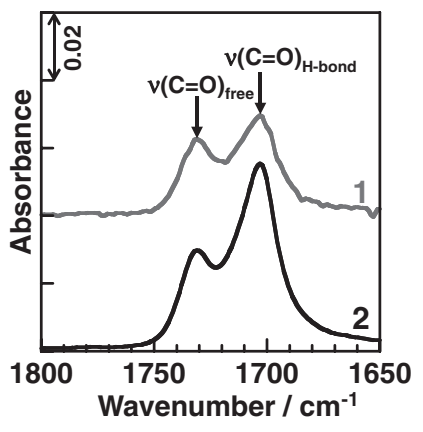

(b)
Figure 1. ATR-FT-IR spectra of PU-34-B and PU-45-B of the region of $\mathrm{NH}$ stretching $(v(\mathrm{NH}))(\mathrm{a})$ and $\mathrm{C}=\mathrm{O}$ stretching $(v(\mathrm{C}=\mathrm{O}))$ (b) bands. Intensity of hydrogen bonded carbonyl stretching band $\left.\left(v(\mathrm{C}=\mathrm{O})_{\mathrm{H}-\text { bond }}\right)\right)$ observed at $1704 \mathrm{~cm}^{-1}$ became stronger with increasing the hard segment content.

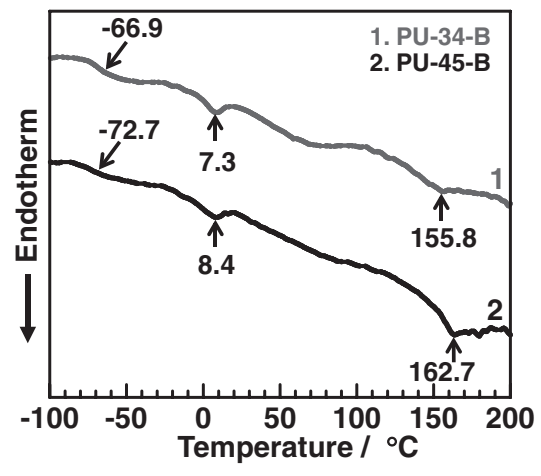

Figure 2. $D S C$ thermograms of $P U-34-B$ and $P U-45-B$. The glass transition temperature $\left(T_{\mathrm{g}}\right)$ of the soft segment chains and the melting point of the crystallized hard segment chains decreased and increased as the hard segment content increased.

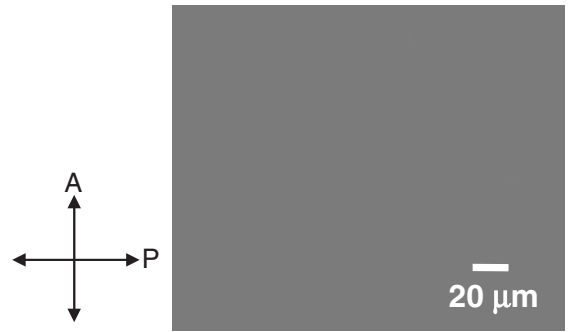

(a)

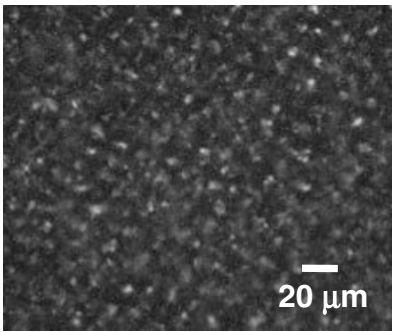

(b)

Figure 3. POM images of (a) PU-34-B and (b) PU-45-B. Bright dots in (b) seem to be spherulite formed in PU-45-B. No specific structure was observed in (a).

regions of $\mathrm{NH}$ stretching $(\nu(\mathrm{NH}))$ (a) and $\mathrm{C}=\mathrm{O}$ stretching $(v(\mathrm{C}=\mathrm{O}))(\mathrm{b})$ bands for PU-34-B and PU-45-B. Generally, free $\mathrm{NH}$ stretching band $\left(v(\mathrm{NH})_{\text {free }}\right)$, hydrogen bonded $\mathrm{NH}$ groups with ether oxygen $\left(v(\mathrm{NH})_{\text {ether }}\right)$ and urethane carbonyl oxygen $\left(v(\mathrm{NH})_{\text {carbonyl }}\right)$ ones are observed at 3450, 3290-3310 and $3300-3350 \mathrm{~cm}^{-1}$, respectively. ${ }^{19,20} v(\mathrm{NH})$ of both PUEs exhibited only $v(\mathrm{NH})_{\text {ether }}$ and $v(\mathrm{NH})_{\text {carbonyl as shown in }}$ Figure 1(a). The peak position of the $v(\mathrm{NH})$ of PU-45-B $\left(3327 \mathrm{~cm}^{-1}\right)$ was slightly higher than for PU-34-B (3320 $\left.\mathrm{cm}^{-1}\right)$. On the contrary, for the $v(\mathrm{C}=\mathrm{O})$, two peaks were observed at around 1704 and $1730 \mathrm{~cm}^{-1}$, which can be assigned to hydrogen bonded carbonyl stretching band $\left.\left(v(\mathrm{C}=\mathrm{O})_{\mathrm{H} \text {-bond }}\right)\right)$ and free one $\left(\nu(\mathrm{C}=\mathrm{O})_{\text {free }}\right){ }^{19,20}$ The ratio of $v(\mathrm{C}=\mathrm{O})_{\mathrm{H} \text {-bond }}$ to $v(\mathrm{C}=\mathrm{O})_{\text {free }}$ for $\mathrm{PU}-45-\mathrm{B}$ were much greater than for PU-34-B, indicating that the ordered aggregation among the hard segment chains were progressed for PU-45-B.

Figure 2 shows the DSC thermograms for PU-34-B and PU45-B. The glass transition temperature $\left(T_{\mathrm{g}}\right)$ and melting of the soft segment chains were observed around -70 and $7{ }^{\circ} \mathrm{C}$, respectively. The $T_{\mathrm{g}}$ of the soft segment chains for PU-45-B were lower than for PU-34-B. On the contrary, the melting of the crystallized hard segment domains were observed around $160^{\circ} \mathrm{C}$ and it increased with the hard segment content. Both FT-IR and DSC data clearly indicate that the degree of microphase separation became stronger with increasing hard segment content.

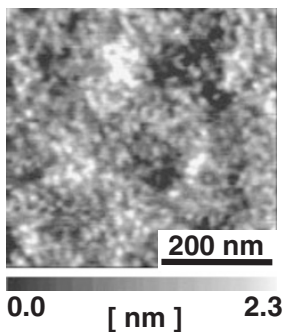

(a)

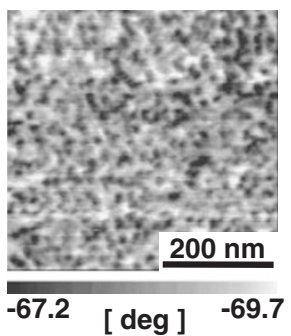

(b)
Figure 4. AFM images of PU-34-B. (a) Topography and (b) phase image. (Scanning area: $500 \times 500 \mathrm{~nm}^{2}$ ) The brighter and darker dots in topographical and phase images correspond to isolated hard segment domains.

Figure 3 shows POM images of (a) PU-34-B and (b) PU-45B. No characteristic image was obtained for PU-34-B, indicating that it possesses homogeneous structure at a macroscopic level. In contrast, one can see the brighter parts of $c a$. 2$5 \mu \mathrm{m}$ in diameter. In our previous study, the PTMG, MDI, BDbased PUEs exhibited the spherulite depending on the hard segment content, synthetic process, annealing condition and so on. ${ }^{21}$ Thus, it seems reasonable to consider that these brighter dots correspond to tiny spherulites formed in PU-45-B. Temperature dependence of POM observation revealed that the spherulite includes much amount of the hard segment 


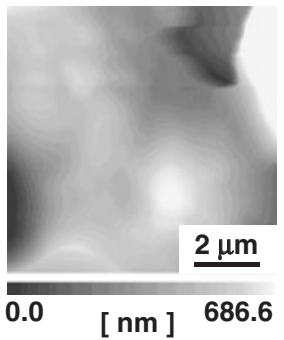

(a)

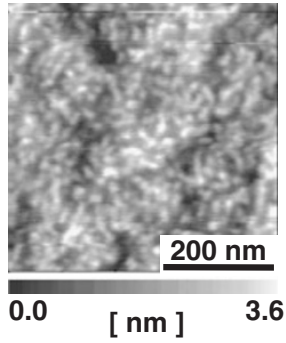

(c)

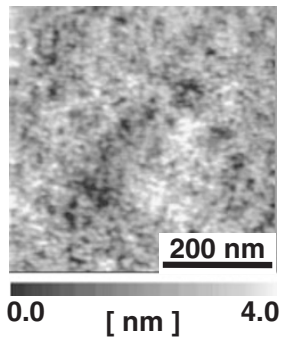

(e)

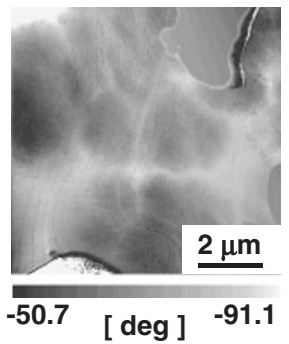

(b)

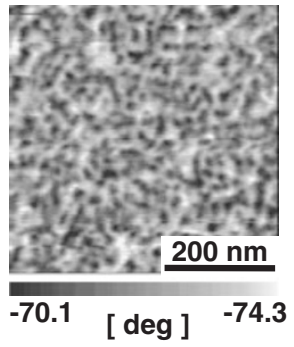

(d)

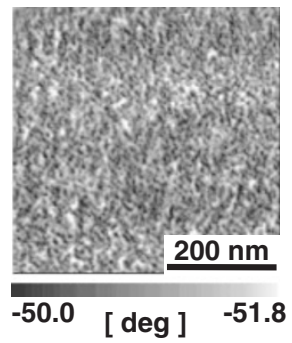

(f)
Figure 5. AFM images of PU-45-B. (a) Topographical and (b) phase image. Note that scanning area of these images is $10 \times 10 \mu \mathrm{m}^{2}$. (c) Topography and (d) phase images of outside of spherulite for PU-45-B observed in Figure 5(b). (e) Topography and (f) phase images of inside of spherulite for PU-45-B observed in Figure 5(b). $\mathrm{PU}-45-\mathrm{B}$ is macrophase-separated into the spherulite domains being composed of a hard segment rich phase and the matrix of a soft segment rich phase. The size of the hard segment domains are quite different. (See Figure 5(d) and 5(f))

component since the spherulite disappeared near the melting temperature of the hard segment domains. ${ }^{21}$ The reason that the different superstructure was formed for these two PUs is thought to be due simply to the difference in the hard segment content. This is because the spherulite includes hard segment component, in other words, the hard segment content should be greater than a certain value for the formation of the spherulite.

Though our curiosity is now on the structure of inside and outside of spherulite, first of all, we observed PU-34-B with no spherulite structure. Parts (a) and (b) of Figure 4 show the AFM topographical and phase images of PU-34-B. Brighter parts in topographical and phase images correspond to higher height and larger phase lag ones, respectively. Isolated higher small dots were clearly observed in Figure 4(a). On the contrary, these higher parts were observed as darker dots in the phase image (Figure 4(b)). The interdomain spacing estimated was $22.6 \mathrm{~nm}$. It is well-known that the PUs possess the

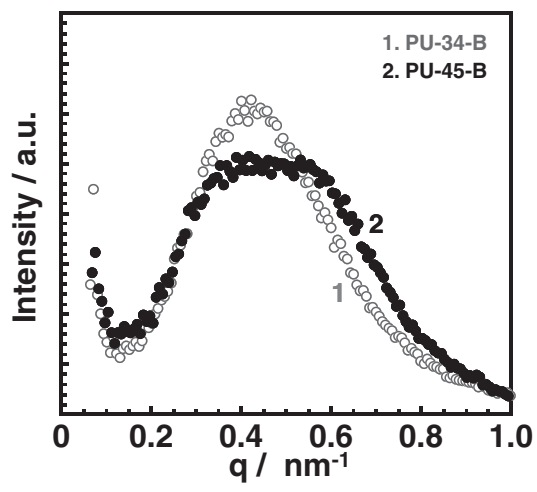

Figure 6. SAXS profiles of PU-34-B and PU-45-B. Scattering peaks, which are assignable to interdomain spacing, were observed. Note that the peak width of PU-45-B was much broader than for PU-34-B.

microphase-separated structure, being composed of hard segment domains and a soft segment matrix for this hard segment content. Therefore, it seems reasonable to consider that the brighter and darker dots in topographical and phase images correspond to isolated hard segment domains.

Figure 5(a) and 5(b) show the AFM topographical and phase images of PU-45-B. Note that the scanning area is $10 \mu \mathrm{m} \times$ $10 \mu \mathrm{m}$ for these AFM images. Topography did not show any trends, in contrast, darker parts of $2-5 \mu \mathrm{m}$ in diameter were clearly observed in the phase image. Since the size of this darker part corresponds to that of brighter part in the POM image, it seems that these darker parts in Figure 5(b) correspond to spherulites. Thus, we tried to observe inside and outside of spherulite with higher resolution. Figure 5(c) and 5(d) show the AFM topographical and phase images of outside of spherulite for PU-45-B. Both topographic and phase images exhibited similar to those for PU-34-B, that is, the isolated hard segment domains surrounded by a soft segment matrix. However, the interdomain spacing $(25.6 \mathrm{~nm})$ was slightly larger than for PU-34-B. In contrast, the AFM images for spherulite inside (Figure 5(e) and 5(f)) showed much smaller hard segment domains. The interdomain spacing estimated is $13.9 \mathrm{~nm}$. Also, the fraction of the hard segment domains looks much higher compared with that for the outside of spherulite, corresponding to the result obtained from temperature dependence POM observation. ${ }^{21}$ Hence, these results suggest that PU-45-B is macrophase-separated into the spherulite domains, being composed of a hard segment rich phase and the matrix of a soft segment rich phase. It is known that large composition and molecular weight disparity of block copolymers tends to macrophase-separate easily. ${ }^{22,23}$ Based on this, it is expected that composition and/or molecular weight distribution in the PUs might have occurred during the polymerization and organization processes because the PU used in this study is as-synthesized and -annealed samples. In other words, there is a possibility that a weak phase separation may have been induced even at the monomer mixture. We will continue to obtain the formation mechanism of the macro- and microphase-separated structure from the monomer state. 


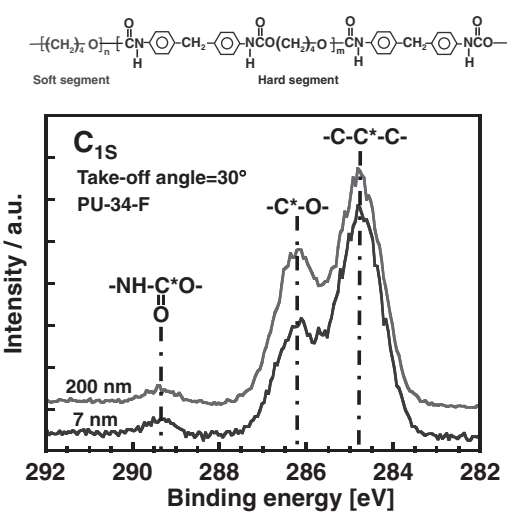

(a)

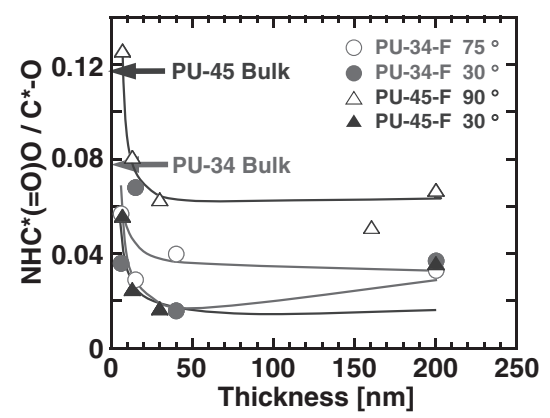

(b)

Figure 7. (a) The XPS $C_{1 s}$ spectra for the thin PU films with $34 \mathrm{wt} \%$ of hard segment content (PU-34-F). The peaks observed at 284.8, 286.5 and $288.0 \mathrm{eV}$ can be assigned to neutral carbon $\left(\mathrm{CC}^{*} \mathrm{C}\right)$, ether carbon $\left(\mathrm{C}^{*} \mathrm{O}\right)$ and urethane carbonyl carbon $\left(\mathrm{NHC}^{*}(=\mathrm{O}) \mathrm{O}\right)$, respectively. As one can easily note, the peak intensity of $\mathrm{NHC}^{*}(=\mathrm{O}) \mathrm{O}$ became larger than for $\mathrm{C}^{*} \mathrm{O}$, indicating that the top layer was covered with lower surface free energy component, PTMG, for thick film and the hard segment domains have come out at the top surface at the smallest thickness. (b) The film thickness dependence of the intensity ratio of $\mathrm{NHC}^{*}(=0) \mathrm{O}$, to $\mathrm{C}^{*} \mathrm{O}\left(\mathrm{NHC}^{*}(=\mathrm{O}) \mathrm{O} / \mathrm{C}^{*} \mathrm{O}\right)$. For the thin film, the ratio increased remarkably.

To confirm discussion on the microphase-separated structure stated above, SAXS measurement was performed. Figure 6 shows SAXS profiles for PU-34-B and PU-45-B. For PU-34-B, only a peak was observed at $0.42 \mathrm{~nm}^{-1}$, and the interdomain spacing was $14.9 \mathrm{~nm}$. On the contrary, two peaks were observed for PU-45-B at 0.36 and $0.55 \mathrm{~nm}^{-1}$. The values of these interdomain spacing were 11.4 and $17.5 \mathrm{~nm}$. The absolute magnitudes obtained by AFM and SAXS were slightly different, but the trend was quite consistent. This is due probably to the convolution effect of AFM tips because the radius of AFM tips and size of the hard segment domains are almost comparable. Therefore, it seems reasonable to conclude that $\mathrm{PU}-45-\mathrm{B}$ is macrophase-separated into the hard segment rich phase (spherulite phase) and soft segment rich one (matrix), and each phase possesses different microphase-separated domain structures.

\section{Thin Films}

Next, we investigated the microphase-separated structure of the PUs films as a function of the film thickness. First of all, the surface chemical composition of the thin PU films was evaluated using XPS. Figure 7(a) shows the XPS $\mathrm{C}_{1 \mathrm{~s}}$ spectra for the thin PU-34 films with the thicknesses of 200 and $7 \mathrm{~nm}$. The peaks observed at $284.8,286.5$ and $288.0 \mathrm{eV}$ can be assigned to neutral carbon $\left(\mathrm{C}-\mathrm{C}^{*}-\mathrm{C}\right)$, ether carbon $\left(\mathrm{C}^{*}-\mathrm{O}\right)$ and urethane carbonyl carbon $\left(\mathrm{NH}-\mathrm{C}^{*}(=\mathrm{O})-\mathrm{O}\right)$, respectively. As one can easily note, the peak intensity of $\mathrm{NH}^{-} \mathrm{C}^{*}(=\mathrm{O})-\mathrm{O}$ and $\mathrm{C}^{*}$-O for the $7 \mathrm{~nm}$ thick film became larger and smaller than for $200 \mathrm{~nm}$ one. This result indicates that the lower surface free energy component, PTMG, was enriched at the top surface for thick film. However, since $\mathrm{NH}-\mathrm{C}^{*}(=\mathrm{O})-\mathrm{O}$ peak was clearly observed for the thicker film even at an emission angle of $30^{\circ}$, the surface was not completely covered with a PTMG layer or there might exist very thin PTMG layer, which is thinner than $5 \mathrm{~nm}$. This is due mainly to the multiblock structure whose block sequence is smaller than $5 \mathrm{~nm}$. Figure 7(b) shows the film thickness dependence of the ratio of urethane carbonyl carbon, to ether carbon $\left(\mathrm{NH}-\mathrm{C}^{*}(=\mathrm{O})-\mathrm{O} / \mathrm{C}^{*}-\mathrm{O}\right)$ for the thin $\mathrm{PU}$ films. The magnitudes of $\mathrm{NH}-\mathrm{C}^{*}(=\mathrm{O})-\mathrm{O} / \mathrm{C}^{*}-\mathrm{O}$ at $10 \mathrm{~nm}$ analytical depth (open symbols) were larger than for $5 \mathrm{~nm}$ analytical depth (filled symbols), indicating PTMG was enriched at the top surface. The magnitude dramatically increased with decreasing film thickness at around $10 \mathrm{~nm}$ thickness and was closed to the magnitude calculated for bulk. This is because the film thickness and analytical depth are almost comparable. As the result, photoelectron was obtained from a whole film. The magnitude for $5 \mathrm{~nm}$ analytical depth was still smaller than for $10 \mathrm{~nm}$ analytical depth. This result indicates that the surface enrichment exists even below $10 \mathrm{~nm}$ film thickness. This is actually reasonable because the layer thickness of PTMG should be less than a few nanometers due to it multiblock structure consisted of a few thousands molecular weight blocks.

We investigated chain structure of the thin PU films using polarized FT-IR measurement. Figure 8 shows (a) schematic representation of a set-up for FT-IR measurement and the FT-IR spectra for the thin PU films with hard segment contents of (b) PU-34-F and (c) PU-45-F at incident angles of 10 and $74^{\circ}$. In the spectra shown here, one can see two peaks at 1704 and $1730 \mathrm{~cm}^{-1}$. These peaks can be assigned to hydrogen bonded carbonyl stretching band $\left(v\left(\mathrm{C}=\mathrm{O}_{\mathrm{H}-\text { bond }}\right)\right)$ and free one $\left(\nu\left(\mathrm{C}=\mathrm{O}_{\text {free }}\right)\right)$, respectively. The intensity ratio of $v\left(\mathrm{C}=\mathrm{O}_{\text {free }}\right)$ peak, to entire $v(\mathrm{C}=\mathrm{O})$ one $\left(I v\left(\mathrm{C}=\mathrm{O}_{\text {free }}\right) / I v(\mathrm{C}=\mathrm{O})\right)$ of PU45-F is smaller than for PU-34-F. This is due simply to the increasing the degree of microphase separation as the hard segment content increases. On the contrary, the magnitude of $I \nu\left(\mathrm{C}=\mathrm{O}_{\text {free }}\right) / I \nu(\mathrm{C}=\mathrm{O})$ for the both films increased with decreasing film thickness at around $10 \mathrm{~nm}$ thickness. This implies the chain structure below $10 \mathrm{~nm}$ thickness is quite different from that of thicker film. Discussion on the chain structure in detail will be given later.

Next, we discuss the molecular orientation of the hard segment chains. $\mathrm{I} v\left(\mathrm{C}=\mathrm{O}_{\text {free }}\right) / \mathrm{I} v(\mathrm{C}=\mathrm{O})$ of both PU films at $74^{\circ}$ exhibited larger magnitude in comparison with that at $10^{\circ}$. The electric field vector of incident infrared beam is almost perpendicular to the film surface at $74^{\circ}$ and the transition 


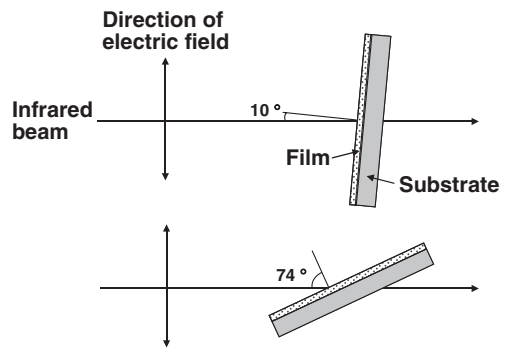

(a)

PU-34-F

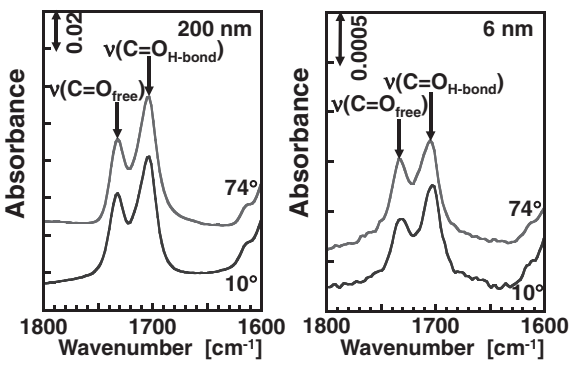

(b)

PU-45-F

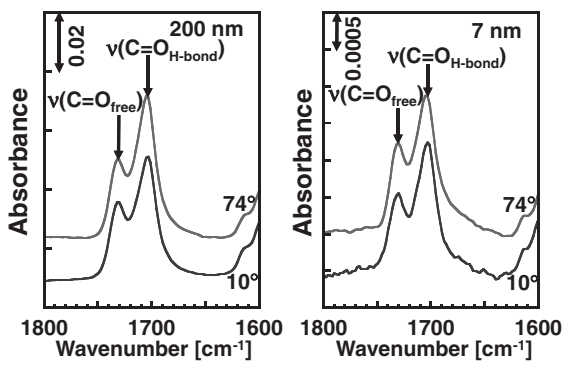

(c)

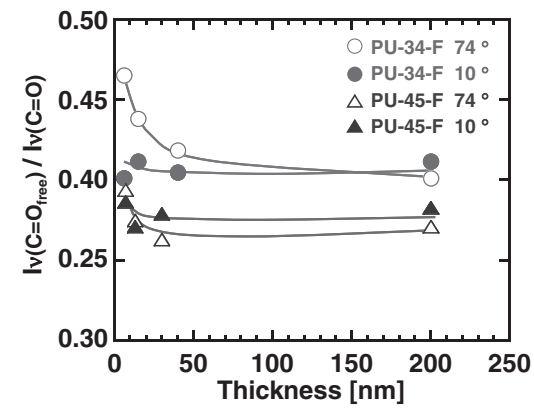

(d)

Figure 8. (a) Schematic representation of Brewster's angle FT-IR set-up. The FT-IR spectra for the thin PU films with (b) 34 and (c) $45 \mathrm{wt} \%$ of hard segment contents at incident angles of 10 and $74^{\circ}$. (d) Intensity ratio of $v\left(\mathrm{C}=\mathrm{O}_{\text {tree }}\right)$ peak, to entire $v(\mathrm{C}=\mathrm{O})$ one for both films. To evaluate the orientation of molecular chains in the PU films, p-polarized infrared beam and two different incident angles were employed. In the spectra shown here, one can see two peaks assigned to hydrogen bonded carbonyl stretching band $\left(\boldsymbol{v}\left(\mathrm{C}=\mathrm{O}_{\mathrm{H} \text {-bond }}\right)\right)$ and free one $\left(\boldsymbol{v}\left(\mathrm{C}=\mathrm{O}_{\text {tree }}\right)\right)$. The intensity ratio of $v\left(\mathrm{C}=\mathrm{O}_{\text {free }}\right)$ peak, to entire $v(\mathrm{C}=\mathrm{O})$ exhibited larger magnitude for the film $6 \mathrm{~nm}$ thick at $74^{\circ}$. This indicates that the hard segment chains orient to the surface normal and/or the hard segment chains with free carbonyl groups oriented along the film/substrate interface with decreasing film thickness.
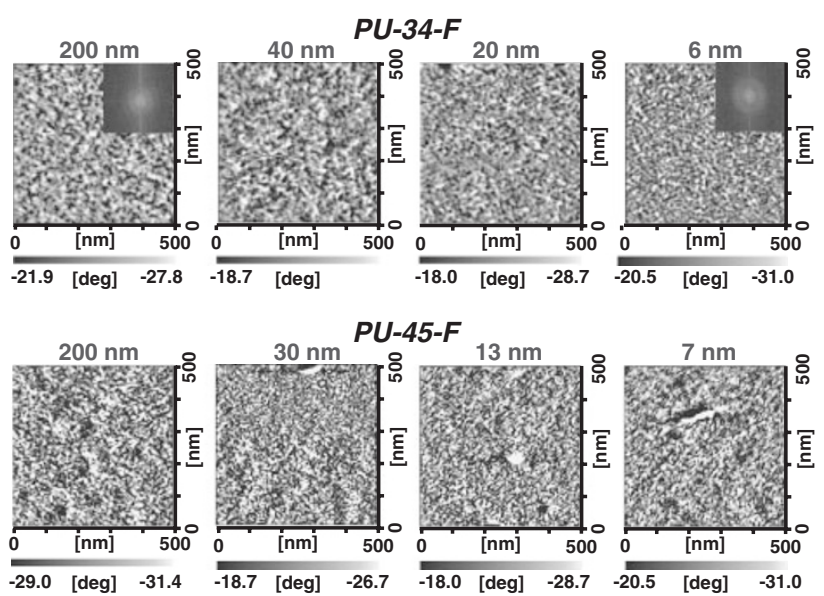

Figure 9. The AFM phase images of the PU films with the hard segment content of 34 and 45 wt \% (PU-34-F and PU-45-F) at 200, 40, 20 and $6 \mathrm{~nm}$ thickness. For PU-34-F, the interdomain spacing above $20 \mathrm{~nm}$ thickness was ca. $27 \mathrm{~nm}$, whereas that was ca. $21 \mathrm{~nm}$ for the $6 \mathrm{~nm}$ thick film by 2 dimensional-fast Fourier transform (2DFFT). On the contrary, the depression of interdomain spacing was observed at larger film thickness for PU-45-F. These results simply related to the relation between space and domain size.

moment of the carbonyl stretching band is perpendicular to the molecular axis. Thus, FT-IR spectra give these two possibilities. One is that the hard segment chains with free carbonyl groups oriented to the parallel to the film/substrate interface with decreasing film thickness. The other one is that the hydrogen bonded hard segment chains oriented to the surface normal. Anyway, dramatic change in chain structure occurred for the thinner film.

To observe the microphase-separated structure of the PU films, we carried out AFM observation. All PU films exhibited homogeneous structure at a large scale observation $(20 \times 20$ $\mu \mathrm{m}^{2}$ ). That is, the spherulite structure, which was observed for the bulk samples, was not observed. Since PUs were once dissolved in THF in the thin film preparation, the superstructure of PUs were totally destructed. In other words, bulk polymerization is indispensable for the formation of spherulite structure. Figure 9 shows the AFM phase images of the PU34 and PU-45 films with various film thicknesses. The brighter part corresponds to the larger phase lag region. It is quite hard to interpret the phase images because these images are affected by some factors, for example, surface elasticity, adhesion force and so on. Concerning the occupied area, it seems reasonable to consider that the darker domains and a brighter matrix correspond to the hard and soft segments, respectively. As one can see the size of microphase-separated structure seems to be different depending on the film thickness, that is, the size of domains decreased with decreasing film thickness. The interdomain spacings of the PU-34 films were estimated to be 27 and $21 \mathrm{~nm}$ for 200 and $6 \mathrm{~nm}$ thicknesses, respectively, by fast Fourier transform (FFT) images. For the PU-34 films, the size of microphase-separated domains was depressed at the thickness of $6 \mathrm{~nm}$. On the contrary, similar things happened for the PU-45 films. However, depression of domain size was 
observed at thicker thickness $(c a .30 \mathrm{~nm})$ in comparison with the PU-34 film $(6 \mathrm{~nm})$. Grazing incident small angle X-ray scattering (GISAXS) measurement also revealed quite similar trend. ${ }^{24}$ The reason that the size of microphase-separated domain decreases at thicker film thickness for the PU-45 films can be explained as follows. The occupied volume of the hard segment component for PU-45-F is greater than for PU-34-F. The hard segment chains of the PU used in this study, -(MDI$\mathrm{BD})_{\mathrm{n}}{ }^{-}$, possess a high crystallizability. ${ }^{25}$ Thus, the formation mechanism of the microphase-separated structure of the PU is deeply related to the crystallization of the hard segment chains. As the film thickness decreases, the space for the crystallization of the hard segment chains became smaller. That is, there is no enough space for the crystallization of the hard segment chains for the thinner films. Therefore, these depressions of domain size are thought to simply relate to the relation between space and domain size.

FT-IR measurement revealed that $I v\left(\mathrm{C}=\mathrm{O}_{\text {free }}\right) / I v(\mathrm{C}=\mathrm{O})$ increased with decreasing film thickness. We are now able to explain the reason. With decreasing film thickness, the size of the microphase separated domains decrease as clarified by AFM, resulting in the amount of the interfacial region between hard segment domains and a soft segment matrix increases. The degree of aggregation of the hard segment chains at the interface might be looser than for the hard segment domains. Thus, it seems reasonable to consider that the aggregation of the hard segment chains became weaker with decreasing film thickness as shown by FT-IR.

\section{CONCLUSIONS}

The microphase-separated structure of the PU bulk and films were investigated. Both sample exhibited the sphere type structure, being consisting of hard segment domains and a soft segment matrix. The structure was dependent on the hard segment content for the PU bulk. For PU-45-B, the PU was macrophase-separated into two phases and each phase possesses the different structure. PU-34-B exhibited one kind of the microphase-separated structure. For the PU thin films, interdomain spacing of the microphase-separated structure decreased below a certain film thickness. This is due simply to restriction of the crystallization of the hard segment domains because of reduction of the space.

Acknowledgment. We are indebted to Dr. Edward J. Kramer, University of California-Santa Barbara in providing the SAXS instrument used in this work. K. K. acknowledges to Dr. Daisuke Kawaguchi and Dr. Yushu Matsushita, Nagoya University, for helpful discussion.
Received: August 18, 2008

Accepted: October 17, 2008

Published: December 5, 2008

\section{REFERENCES}

1. H. N. Ng, A. E. Allegrezza, R. W. Seymour, and S. L. Cooper, Polymer, 14, 255 (1973).

2. C. Li and S. L. Cooper, Polymer, 31, 3 (1990).

3. R. W. Seymour and S. L. Cooper, Macromolecules, 6, 48 (1973).

4. J. T. Koberstein and R. S. Stein, J. Polym. Sci., Polym. Phys. Ed., 21, 1439 (1983).

5. J. T. Koberstein and T. P. Russell, Macromolecules, 19, 714 (1986).

6. M. Furukawa, M. Komiyama, and T. Yokoyama, Angew. Makromol. Chem., 240, 205 (1996).

7. T. Okazaki, M. Furukawa, and T. Yokoyama, Polym. J., 29, 617 (1997).

8. M. Furukawa, Y. Hamada, and K. Kojio, J. Polym. Sci., Polym. Phys. Ed., 41, 2355 (2003).

9. K. Kojio, T. Fukumaru, and M. Furukawa, Macromolecules, 37, 3287 (2004).

10. K. Kojio, Y. Nonaka, and M. Furukawa, J. Polym. Sci., Polym. Phys. Ed., 42, 4448 (2004).

11. K. Kojio, S. Nakamura, and M. Furukawa, Polymer, 45, 8147 (2004).

12. M. Furukawa, Y. Mitsui, T. Fukumaru, and K. Kojio, Polymer, 46, 10817 (2005)

13. S. Yamasaki, D. Nishiguchi, K. Kojio, and M. Furukawa, J. Polym. Sci., Polym. Phys. Ed., 45, 800 (2007).

14. S. Yamasaki, D. Nishiguchi, K. Kojio, and M. Furukawa, Polymer, 48, 4793 (2007).

15. K. Kojio, S. Nakashima, and M. Furukawa, Polymer, 48, 997 (2007).

16. K. Kojio, S. Nakamura, and M. Furukawa, J. Polym. Sci., Polym. Phys. Ed., 46, 2054 (2008).

17. J. H. Silver, E. Karayianni, and S. L. Cooper, J. Colloid Interface Sci., 178, 219 (1996).

18. C. Harrison, P. M. Chaikin, D. A. Huse, R. A. Register, D. H. Adamson, A. Daniel, E. Huang, P. Mansky, T. P. Russell, C. J. Hawker, D. A. Egolf, I. V. Melnikov, and E. Bodenschatz, Macromolecules, 33, 857 (2000).

19. H. S. Lee, Y. K. Wang, and S. L. Hsu, Macromolecules, 20, 2089 (1987).

20. C. M. Brunette, S. L. Hsu, and W. J. MacKnight, Macromolecules, 15, 71 (1982).

21. M. Furukawa and T. Yokoyama, unpublished results.

22. a) T. Hashimoto, K. Yamasaki, S. Koizumi, and H. Hasegawa, Macromolecules, 26, 2895 (1993).

b) F. Court and T. Hashimoto, Macromolecules, 34, 2536 (2001).

23. a) Y. Matsushita, A. Noro, M. Inuma, J. Suzuki, H. Ohtani, and A. Takano, Macromolecules, 36, 8074 (2003).

b) A. Noro, D. Cho, A. Takano, and Y. Matsushita, Macromolecules, 38, 4371 (2005).

c) A. Noro, M. Iinuma, J. Suzuki, A. Takano, and Y. Matsushita, Macromolecules, 37, 3804 (2004).

d) A. Noro, M. Okuda, F. Odamaki, D. Kawaguchi, N. Torikai, A. Takano, and Y. Matsushita, Macromolecules, 39, 7654 (2006).

24. K. Kojio, Y. Uchiba, Y. Mitsui, M. Furukawa, S. Sasaki, H. Matsunaga, and H. Okuda, Macromolecules, 40, 2625 (2007).

25. J. Blackwell and C. D. Lee, J. Polym. Sci., Polym. Phys. Ed., 22, 759 (1984). 